\title{
The Partnership Of EDGAR Online And XBRL - Should Compustat Care?
}

Pavani Tallapally, Slippery Rock University, USA

Michael S. Luehlfing, Louisiana Tech University, USA

Madhu Motha, Butler County Community College, USA

\begin{abstract}
Until EDGAR Online began operational, Compustat was (arguably) the only provider of financial statement information with accompanying database development capabilities. While EDGAR Online has received relatively little attention in the literature to date, we posit that the use of Edgar Online could flourish given the recent XBRL (eXtensible Business Reporting Language) reporting mandate of the SEC (Securities and Exchange Commission). In this regard, we identify the differences between Compustat and EDGAR Online in terms of data presentation as well as database development capabilities and product pricing. Our results suggest that differences exist between data presentation, database development capabilities as well as product pricing. In turn, we believe that such differences may facilitate EDGAR Online's competitive position with respect to Compustat.
\end{abstract}

Keywords: Compustat; Databases; EDGAR; Edgar Online; XBRL

\section{INTRODUCTION}

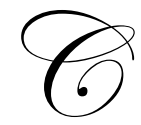

ompustat is (arguably) the most dominant provider (in terms of market share) of financial statement information with accompanying database development capabilities. However, given the recent XBRL (eXtensible Business Reporting Language) reporting mandate of the SEC (Securities and Exchange Commission), we believe that EDGAR Online could position itself to take market share from Compustat in the future. Specifically, we posit that differences exist between Compustat and EDGAR Online in terms of data presentation as well as database development capabilities and product pricing may facilitate EDGAR Online's competitive position with respect to Compustat.

Our analysis is organized as follows. We begin by providing an overview of Compustat, EDGAR and EDGAR Online. Therafter, we analyze the differences between Compustat and EDGAR Online in terms of data presentation as well as database development capabilities and product pricing. We conclude with a commentary based on the results of our analysis.

\section{BACKGROUND: COMPUSTAT, EDGAR, AND EDGAR ONLINE}

In this section of the paper we provide a background overview of Compustat, EDGAR, and EDGAR Online. Our analysis of differences between Compustat and EDGAR Online is found in the next section of the paper.

\section{Compustat}

Compustat (www.compustat.com) provides accounting and market data to academic researchers and financial professionals. Compustat data can be obtained from Compustat North America-Wharton Research Data Services (a.k.a., Wharton Data Services). The following description of the Compustat North America database is provided by Wharton Data Services (http://wrds.wharton.upenn.edu): 
Compustat North America is a database of U.S. and Canadian fundamental and market information on more than 24,000 active and inactive publicly held companies. It provides more than 300 annual and 100 quarterly Income Statement, Balance Sheet, Statement of Cash Flows, and supplemental data items. Standard \& Poor's offers a selection of Compustat North America files that are available in both annual and quarterly formats. The industrial annual formats offer both historical and restated data. The industrial quarterly formats offer restated data as reported by the company. The restated data allows analysts to compare current and prior years' results on a comparable basis and determine financial trends and growth rates. For most companies, annual and quarterly data are available for a maximum of 20 years and 48 quarters.

Compustat is sponsored by Standard and Poor's. In contrast EDGAR (a.k.a., Electronic Data Gathering, Analysis, and Retrieval) is sponsored by the SEC.

\section{EDGAR}

The two excerpts found immediately below summarize the existence of EDGAR from 1984 to 2008 (http://help.edgar-online.com/edgar/history.asp?site=pro).

In 1984, the SEC allocated \$30 million to start the EDGAR (Electronic Data Gathering Analysis and Retrieval) pilot program. Its purpose was to create an electronically accessible database providing a more efficient and less costly method whereby the investing public could get the information it needed. A gradual phase-in schedule was established mandating public corporations to file SEC documents electronically. As of fall 1995, more than 92\% of all public companies were filing with EDGAR.

Since May of 1996, all reporting companies have been required to file electronically. This new method of filing has enormous implications for the investment community because once a document is filed, the information is immediately available to anyone who has the computer capacity to "talk" to the EDGAR database.

In 2008, the SEC announced plans to require that all publicly traded US companies file their financial statements using a technology called XBRL (Anonymous, 2008; and WebStaff, 2009). XBRL (eXtensible Business Reporting Language) is a worldwide standard for the publishing, exchange, and analysis of financial reports and data (www.xbrl.org).

\section{EDGAR Online}

The essence of EDGAR Online can be summarized as follows (http://help.edgaronline.com/edgar/history.asp?site=pro):

EDGAR Online is the highest traffic Web-based provider of real-time SEC filings. Through our various web based products we offer easy access to many resources that allow both professional and individual investors the ability to extract and manage the valuable information found in the SEC's EDGAR (Electronic Data Gathering Analysis and Retrieval) filings. EDGAR Pro is a privately held service by EDGAR Online, Inc.. The SEC's EDGAR system is government-run and supplies filings to EDGAR Online, Inc. for distribution over the Internet.

Significantly, the last sentence (in the above excerpt) alludes to the relationship between EDGAR and EDGAR Online. First, EDGAR is "government-run" (not run by EDGAR Online). And second, EDGAR Online obtains EDGAR data from the government (i.e., the SEC). Admittedly, Compustat can also obtain EDGAR data from the SEC.

\section{ANALYSIS: COMPUSTAT VERSUS EDGAR ONLINE (XBRL)}

In this section of the paper we document our analysis of differences between Compustat and EDGAR Online. We focus on three areas: data presentation, database development capabilities, and product pricing. 


\section{Data Presentation}

Research (Miguel, 1977; Kinney and Swanson, 1993; and Yang et al. 2003) suggests that accounting data provided by some data intermediaries (e.g., Compustat) differs from data provided in annual financial statements. We believe that the primary reason for such differences rests with certain data specification practices peculiar to each data intermediary. For example, Compustat edits the "as reported" financial statement data of a company by using a proprietary data standardization process as described in the following excerpt (www.compustat.com):

Our internal research team rigorously examines original company sources by carefully extracting financial information, removing reporting biases and reconciling data discrepancies. After collecting data from diverse sources, we standardize it by financial statement and by specific data item definition, preparing information that is comparable across companies, industries, time periods and sectors. This standardized presentation makes it easier to identify companies with similar characteristics, such as capital structure and operating performance and is designed to complement how the data [are] used. Additionally we analyze financial statement notes to provide detailed breakouts to gain additional insight overlooked by other companies.

In contrast, EDGAR Online (http://www.edgar-online.com/DataDocuments/FundamentalData.aspx) provides both "normalized financial data" as well as "non-standardized data" (that is, "as reported" financial data). In this regard, we analyze the extent of such differences in data presentation by comparing cost of goods sold data (Compustat versus EDGAR Online) for the twenty-six manufacturing companies included in the DOW 30 companies. Each of these twenty-six companies reported their financial data using the "Commercial and Industrial" XBRL taxonomy (versus the Banking and Savings Institutions" XBRL Taxonomy or the "Insurance" XBRL Taxonomy). The Compustat data was obtained via Research Insight while the EDGAR Online data was obtained via I-Metrix.

Table 1: Dow 30 Companies (Ticker Symbols)

\begin{tabular}{|c|c|}
\hline Company & Company \\
\hline 3M Co. (MMM) & Home Depot, Inc. (HD) \\
\hline Alcoa Inc. (AA) & Intel Corp. (INTC) \\
\hline American Express Co. (AXP) \# & International Business Machine. (IBM) \\
\hline AT\&T Inc (T) & J.P. Morgan Chase \& Co. (JPM) \# \\
\hline Bank of America Corp. (BAC) \# & Johnson \& Johnson (JNJ) \\
\hline Boeing Co. (BA) & Kraft Foods Inc. (KFT) \\
\hline Caterpillar, Inc. (CAT) & McDonalds Corp. (MCD) \\
\hline Chevron Corp. (CVX) & Merck \& Co. Inc. (MRK) \\
\hline Cisco Systems Inc. (CSCO) & Microsoft Corp. (MSFT) \\
\hline Coca-Cola Co. $(\mathrm{KO})$ & Pfizer Inc. (PFE) \\
\hline Disney Co. (DIS) & Procter \& Gamble Co. (PG) \\
\hline DuPont (E.I.) deNemours \& Co. (DD) & Travelers' Companies Inc. (TRV) \# \\
\hline Exxon Mobil Corp. (XOM) & United Technologies Corp. (UTX) \\
\hline General Electric Co. (GE) & Verizon Communications Inc. (VZ) \\
\hline Hewlett-Packard Co. (HPQ) & Wal-Mart Stores Inc. (WMT) \\
\hline
\end{tabular}

The Dow 30 companies are listed in Table 1. Additionally, the results of the initial comparisons of Cost of Goods Sold amounts included in the sample are provided in Table 2. As indicated in Table 3, only one company reported the same Cost of Goods Sold amount by both Compustat and EDGAR Online (that is, AT\&T, Inc.). As indicated in Table 4, Compustat reported higher Cost of Goods Sold amounts (than EDGAR Online) for two companies (that is, Chevron, and Exxon). As indicated in Table 5, Compustat reported lower Cost of Goods Sold amounts (than EDGAR Online) for the other twenty-three companies in the sample. Summary statistics for the data differences between Compustat and EDGAR Online are provided in Table 6. The mean difference for twenty-three companies where the EDGAR Online reported Cost of Goods Sold amounts were higher than the Compustat 
reported amounts was $-\$ 2,887.25$. In contrast, the mean difference for the two companies where Compustat reported a higher Cost of Goods Sold amount than EDGAR Online was $\$ 22,150.50$. At first glance, while the aggregate average difference of $-\$ 850.22$ (for the entire sample of twenty-six companies) may appear rather trivial, this "portfolio" difference resulted from the netting of both positive and negative non-trivial "individual" differences.

Table 2: Cost of Goods Sold Amounts-Initial Comparisons

\begin{tabular}{|c|c|c|c|c|c|}
\hline Symbol & Year End & COMPUSTAT & $\begin{array}{c}\text { EDGAR } \\
\text { Online } \\
\text { (normalized) }\end{array}$ & Difference & $\begin{array}{c}\text { Percentage of } \\
\text { EDGAR Online } \\
\text { Amount* }\end{array}$ \\
\hline MMM & $12 / 31 / 09$ & $\$ 10,857.00$ & $\$ 12,109.00$ & $-\$ 1,252.00$ & $-10.34 \%$ \\
\hline AA & $12 / 31 / 09$ & $\$ 16,652.00$ & $\$ 16,902.00$ & $-\$ 250.00$ & $-1.48 \%$ \\
\hline $\mathrm{T}$ & $12 / 31 / 09$ & $\$ 50,405.00$ & $\$ 50,405.00$ & $\$ 0.00$ & $0.00 \%$ \\
\hline $\mathrm{BA}$ & $12 / 31 / 09$ & $\$ 55,092.00$ & $\$ 56,540.00 \#$ & $-\$ 1,448.00$ & $-2.56 \%$ \\
\hline CAT & $12 / 31 / 09$ & $\$ 22,284.00$ & $\$ 24,931.00 \#$ & $-\$ 2,647.00$ & $-10.62 \%$ \\
\hline CVX & $12 / 31 / 09$ & $\$ 126,992.00$ & $\$ 117,510.00 \#$ & $\$ 9,482.00$ & $8.07 \%$ \\
\hline $\mathrm{CSCO}$ & $7 / 31 / 09$ & $\$ 11,788.00$ & $\$ 13,023.00$ & $-\$ 1,235.00$ & $-9.48 \%$ \\
\hline $\mathrm{KO}$ & $12 / 31 / 09$ & $\$ 10,002.00$ & $\$ 11,088.00$ & $-\$ 1,086.00$ & $-9.79 \%$ \\
\hline DIS & 9/30/09 & $\$ 28,821.00$ & $\$ 30,452.00$ & $-\$ 1,631.00$ & $-5.36 \%$ \\
\hline $\mathrm{DD}$ & $12 / 31 / 09$ & $\$ 18,255.00$ & $\$ 19,708.00$ & $-\$ 1,453.00$ & $-7.37 \%$ \\
\hline $\mathrm{XOM}$ & $12 / 31 / 09$ & $\$ 220,652.00$ & $\$ 185,833.00$ & $\$ 34,819.00$ & $18.74 \%$ \\
\hline GE & $12 / 31 / 09$ & $\$ 66,202.00$ & $\$ 78,938.00 \#$ & $-\$ 12,736.00$ & $-16.13 \%$ \\
\hline HPQ & $10 / 31 / 09$ & $\$ 84,322.00$ & $\$ 87,524.00 \#$ & $-\$ 3,202.00$ & $-3.66 \%$ \\
\hline $\mathrm{HD}$ & $1 / 31 / 10$ & $\$ 43,571.00$ & $\$ 43,764.00$ & $-\$ 193.00$ & $-0.44 \%$ \\
\hline INTC & $12 / 31 / 09$ & $\$ 10,549.00$ & $\$ 15,566.00$ & $-\$ 5,017.00$ & $-32.23 \%$ \\
\hline IBM & $12 / 31 / 09$ & $\$ 46,272.00$ & $\$ 51,973.00 \#$ & $-\$ 5,701.00$ & $-10.97 \%$ \\
\hline JNJ & $12 / 31 / 09$ & $\$ 15,560.00$ & $\$ 18,447.00$ & $-\$ 2,887.00$ & $-15.65 \%$ \\
\hline KFT & $12 / 31 / 09$ & $\$ 24,881.00$ & $\$ 25,786.00$ & $-\$ 905.00$ & $-3.51 \%$ \\
\hline MCD & $12 / 31 / 09$ & $\$ 12,792.10$ & $\$ 13,952.90$ & $-\$ 1,160.80$ & $-8.32 \%$ \\
\hline MRK & $12 / 31 / 09$ & $\$ 3,693.10$ & $\$ 9,019.00 @$ & $-\$ 5,325.90$ & $-59.05 \%$ \\
\hline MSFT & $6 / 30 / 10$ & $\$ 9,888.00$ & $\$ 12,395.00$ & $-\$ 2,507.00$ & $-20.23 \%$ \\
\hline PFE & $12 / 31 / 09$ & $\$ 6,769.00$ & $\$ 8,888.00$ & $-\$ 2,119.00$ & $-23.84 \%$ \\
\hline PG & $6 / 30 / 10$ & $\$ 34,811.00$ & $\$ 37,919.00$ & $-\$ 3,108.00$ & $-8.20 \%$ \\
\hline UTX & $12 / 31 / 09$ & $\$ 37,242.00$ & $\$ 38,861.00$ & $-\$ 1,619.00$ & $-4.17 \%$ \\
\hline $\mathrm{VZ}$ & $12 / 31 / 09$ & $\$ 42,622.00$ & $\$ 44,299.00$ & $-\$ 1,677.00$ & $-3.79 \%$ \\
\hline WMT & $1 / 31 / 09$ & $\$ 297,500.00$ & $\$ 304,657.00$ & $-\$ 7,157.00$ & $-2.35 \%$ \\
\hline
\end{tabular}

Notes:

* Difference / EDGAR Online Cost of Goods Sold amount.

\# Amount differs from "as reported" XBRL amount; difference was reconcilable.

@ Amount differs from "as reported" XBRL amount due to rounding.

Table 3: Cost of Goods Sold Comparisons-No Differences

\begin{tabular}{|l|c|c|c|c|c|}
\hline Symbol & Year End & COMPUSTAT & $\begin{array}{c}\text { EDGAR } \\
\text { Online } \\
\text { (normalized) }\end{array}$ & Difference & $\begin{array}{c}\text { Percentage of } \\
\text { EDGAR Online } \\
\text { Amount* }\end{array}$ \\
\hline $\mathrm{T}$ & $12 / 31 / 09$ & $\$ 50,405.00$ & $\$ 50,405.00$ & $\$ 0.00$ & $0.00 \%$ \\
\hline
\end{tabular}

Note: * Difference / EDGAR Online Cost of Goods Sold amount

Table 4: Cost of Goods Sold Comparisons-Positive Differences

\begin{tabular}{|l|c|c|c|c|c|}
\hline Symbol & Year End & COMPUSTAT & $\begin{array}{c}\text { EDGAR } \\
\text { Online } \\
\text { (normalized) }\end{array}$ & Difference & $\begin{array}{c}\text { Percentage of } \\
\text { EDGAR Online } \\
\text { Amount* }\end{array}$ \\
\hline CVX & $12 / 31 / 09$ & $\$ 126,992.00$ & $\$ 117,510.00$ & $\$ 9,482.00$ & $8.07 \%$ \\
\hline XOM & $12 / 31 / 09$ & $\$ 220,652.00$ & $\$ 185,833.00$ & $\$ 34,819.00$ & $18.74 \%$ \\
\hline
\end{tabular}

Note: * Difference / EDGAR Online Cost of Goods Sold amount 
Table 5: Cost of Goods Sold Comparisons-Negative Differences

\begin{tabular}{|l|c|c|c|c|c|}
\hline Symbol & Year End & COMPUSTAT & $\begin{array}{c}\text { EDGAR } \\
\text { Online } \\
\text { (normalized) }\end{array}$ & Difference & $\begin{array}{c}\text { Percentage of } \\
\text { EDGAR Online } \\
\text { Amount* }\end{array}$ \\
\hline MMM & $12 / 31 / 09$ & $\$ 10,857.00$ & $\$ 12,109.00$ & $-\$ 1,252.00$ & $-10.34 \%$ \\
\hline AA & $12 / 31 / 09$ & $\$ 16,652.00$ & $\$ 16,902.00$ & $-\$ 250.00$ & $-1.48 \%$ \\
\hline BA & $12 / 31 / 09$ & $\$ 55,092.00$ & $\$ 56,540.00$ & $-\$ 1,448.00$ & $-2.56 \%$ \\
\hline CAT & $12 / 31 / 09$ & $\$ 22,284.00$ & $\$ 24,931.00$ & $-\$ 2,647.00$ & $-10.62 \%$ \\
\hline CSCO & $7 / 31 / 09$ & $\$ 11,788.00$ & $\$ 13,023.00$ & $-\$ 1,235.00$ & $-9.48 \%$ \\
\hline KO & $12 / 31 / 09$ & $\$ 10,002.00$ & $\$ 11,088.00$ & $-\$ 1,086.00$ & $-9.79 \%$ \\
\hline DIS & $9 / 30 / 09$ & $\$ 28,821.00$ & $\$ 30,452.00$ & $-\$ 1,631.00$ & $-5.36 \%$ \\
\hline DD & $12 / 31 / 09$ & $\$ 18,255.00$ & $\$ 19,708.00$ & $-\$ 1,453.00$ & $-7.37 \%$ \\
\hline GE & $12 / 31 / 09$ & $\$ 66,202.00$ & $\$ 78,938.00$ & $-\$ 12,736.00$ & $-16.13 \%$ \\
\hline HPQ & $10 / 31 / 09$ & $\$ 84,322.00$ & $\$ 87,524.00$ & $-\$ 3,202.00$ & $-3.66 \%$ \\
\hline HD & $1 / 31 / 10$ & $\$ 43,571.00$ & $\$ 43,764.00$ & $-\$ 193.00$ & $-0.44 \%$ \\
\hline INTC & $12 / 31 / 09$ & $\$ 10,549.00$ & $\$ 15,566.00$ & $-\$ 5,017.00$ & $-32.23 \%$ \\
\hline IBM & $12 / 31 / 09$ & $\$ 46,272.00$ & $\$ 51,973.00$ & $-\$ 5,701.00$ & $-10.97 \%$ \\
\hline JNJ & $12 / 31 / 09$ & $\$ 15,560.00$ & $\$ 18,447.00$ & $-\$ 2,887.00$ & $-15.65 \%$ \\
\hline KFT & $12 / 31 / 09$ & $\$ 24,881.00$ & $\$ 25,786.00$ & $-\$ 905.00$ & $-3.51 \%$ \\
\hline MCD & $12 / 31 / 09$ & $\$ 12,792.10$ & $\$ 13,952.90$ & $-\$ 1,160.80$ & $-8.32 \%$ \\
\hline MRK & $12 / 31 / 09$ & $\$ 3,693.10$ & $\$ 9,109.00$ & $-\$ 5,415.90$ & $-59.46 \%$ \\
\hline MSFT & $6 / 30 / 10$ & $\$ 9,888.00$ & $\$ 12,395.00$ & $-\$ 2,507.00$ & $-20.23 \%$ \\
\hline PFE & $12 / 31 / 09$ & $\$ 6,769.00$ & $\$ 8,888.00$ & $-\$ 2,119.00$ & $-23.84 \%$ \\
\hline PG & $6 / 30 / 10$ & $\$ 34,811.00$ & $\$ 37,919.00$ & $-\$ 3,108.00$ & $-8.20 \%$ \\
\hline UTX & $12 / 31 / 09$ & $\$ 37,242.00$ & $\$ 38,861.00$ & $-\$ 1,619.00$ & $-4.17 \%$ \\
\hline VZ & $12 / 31 / 09$ & $\$ 42,622.00$ & $\$ 44,299.00$ & $-\$ 1,677.00$ & $-3.79 \%$ \\
\hline WMT & $1 / 31 / 09$ & $\$ 297,500.00$ & $\$ 304,657.00$ & $-\$ 7,157.00$ & $-2.35 \%$ \\
\hline NOF & & & & \\
\hline
\end{tabular}

Note: $\quad *$ Difference / EDGAR Online Cost of Goods Sold amount

Table 6: Cost of Goods Sold Comparisons-Summary

\begin{tabular}{|l|c|c|c|r|r|}
\hline $\begin{array}{c}\text { Sample/ } \\
\text { Subsample } \\
\text { Description }\end{array}$ & $\begin{array}{c}\text { Sample/ } \\
\text { Subsample } \\
\text { Size }\end{array}$ & $\begin{array}{c}\text { Mean } \\
\text { Difference }\end{array}$ & $\begin{array}{c}\text { Standard } \\
\text { Deviation }\end{array}$ & Range (High) & Range (Low) \\
\hline No Differences* & 1 & $\$ 0.00$ & $\$ 0.00$ & $\$ 0.00$ & $\$ 0.00$ \\
\hline Positive Differences* & 2 & $\$ 22,150.50$ & $\$ 17,915.96$ & $\$ 34,819.00$ & $\$ 9,482.00$ \\
\hline Negative Differences* & 23 & $-\$ 2,887.25$ & $\$ 2,808.82$ & $-\$ 193.00$ & $-\$ 12,736.00$ \\
\hline All Manufacturing* & 26 & $-\$ 850.22$ & $\$ 8,121.03$ & $\$ 34,819.00$ & $-\$ 12,736.00$ \\
\hline
\end{tabular}

Note: *COMPUSTAT minus EDGAR Online.

We were not able to reconcile the differences noted between Compustat and Edgar Online. However, since the net income amounts reported by both Compustat and EDGAR Online were the same (i.e., were equal) for each company in the sample, it is assumed that the differences noted in the reported Cost of Goods Sold amounts were offset by the cumulative (but unobservable differences) related to components of other income statement debit and/or credit balances. Given that differences exist, and given that the differences (are assumed to) relate to the proprietary accounting data standardization process employed by Compustat as well as the data normalization procedures employed by EDGAR Online, it may be that researchers as well as practitioners may want to extract financial statement data directly from the SEC website. Admittedly, we were able to reconcile differences between the "normalized" and "as reported" data provided by EDGAR Online.

\section{Database Development Capabilities}

Given that the XBRL data provided on the SEC website does not provide database development capabilities, in some cases researchers as well as practitioners may save time by purchasing the Compustat and/or EDGAR Online products (for example, if such individuals wish to develop comprehensive mathematical models). However, if financial statement data is only needed for one or a few companies, then it may be that researchers as 
well as practitioners may want to merely extract financial statement data directly from the SEC website (on an ad hoc basis).

As described in Exhibit One, EDGAR Online has a portfolio of patents with respect to it database development capabilities. Arguably, the technologies associated with this porfolio of patents represents a non-trivial difference in database development capabilities between Compustat and EDGAR Online. Admittedly, the portfolio of patents does not imply that EDGAR Online has a superior database capability versus Compustat. Anecdotally speaking, we know many researchers who rely on Compustat and few researchers (besides ourselves) who rely on EDGAR Online. In this regard, it is our belief that actions often speak louder than words.

\section{EXHIBIT ONE: PORTFOLIO OF PATENTS-EDGAR ONLINE}

EDGAR Online Awarded U.S. Patent for System and Method for Rendering Data Enables Intelligent Navigation of Financial Reports

ROCKVILLE, Md., March 31, 2011 /PRNewswire/ -- EDGAR(R) Online, Inc. (Nasdaq: EDGR), a leading global provider of XBRL (eXtensible Business Reporting Language) software, services and data, has been granted U.S. Patent 7,917,841 entitled "System and Method for Rendering Data" on March 29, 2011. The patent covers the semantic analysis of notes to financial statements and the association of those notes to related items in a primary financial statement.

The patent recognizes and protects EDGAR Online's method for allowing the categorization and cross-referencing of data within financial documents by analyzing notes to financial statements and presenting the information in a concise format. Analysts and investors currently see the benefits of this method within EDGAR Online's I-Metrix(R) suite of products, a range of online solutions that provide accurate company information and detailed XBRL-tagged financials for the more than 12,000 companies that file with the U.S. Securities and Exchange Commission (SEC).

"EDGAR Online is dedicated to creating expert solutions that allow financial analysts and investors to locate, evaluate and use detailed financial information for benchmarking and research purposes," stated Stefan Chopin, chief technology officer of EDGAR Online and an inventor of the method that received the patent. "This patent issuance reinforces our commitment to improving the flow of business information."

This patent extends EDGAR Online's patent portfolio that also includes the XBRL patent, U.S. Patent 6,947,947, issued in 2005 to UBmatrix, Inc. entitled "Method for Adding Metadata to Data" and U.S. Patent 7,877,678, issued on January 25, 2011 entitled "System and Method for Rendering of Financial Data."

Source: http://online.wsj.com/article/PR-CO-20110331-906437.html

\section{Product Pricing}

The pricing information (provided in Exhibit Two and Exhibit Three) was obtained from both Compustat and EDGAR Online on an ad hoc basis. Accordingly, such information may not be generalizable to all database purchasing decisions. However, the information does provide a basis for developing preliminary opinions. In this regard, it appears that there are non-trivial differences in product pricing. However, such differences may be justifiable under a various combination of circumstances (e.g., number if users, nature of database needs, length of time needed to access data, etc.).

\section{EXHIBIT TWO: PRODUCT PRICING-COMPUSTAT}

The academic price for the Compustat North American database (which includes foreign ADR's companies) through the Research Insight software is $\$ 17,325$ per year. We offer $30 \%$ off of standard academic pricing for universities with Bachelor's level programs only. We also offer multi-year licenses with a 5\% off discount for each year of the multi-year period and locked-in prices, etc. 
Additionally, we offer a Research Insight (Global) database; which is highly discounted as an add-on to the North American database above. And we offer, an extended Back Data add-on service through Research Insight also.

And, at Standard \& Poor's, we offer other data alternatives to Compustat, such as our Capital IQ service which begins at lower price points that Compustat (Capital IQ licenses begin at \$7,500 and up total per year). Capital IQ is licensed based either by the number of specified users (particularly helpful for faculty) and/or by the number of workstations.

Source: E-mail from representative

\section{EXHIBIT THREE: PRODUCT PRICING-EDGAR ONLINE}

iMetrix will provide professors in the classroom and students on and off-campus with a low cost, highly mobile and very easy to use financial database for use in the studies by providing a flexible online website for financial data research and iMetrix's Excel Add-in to deliver data directly into the financial model. Users can use the iMetrix model Library with ready-to-use financial models for peer benchmarking, valuation, discounted cash flow and more, or they create their own models within Excel. iMetrix also provides both financial screening tools that leverage thousands of data elements and mathematical calculations to identify companies that match the user's criteria.

Additionally, the iMetrix solution will supply the students with working knowledge of a next generation technology in XBRL and will arm the graduates with a unique set of knowledge and skills as they enter the highly competitive marketplace upon graduation.

The quotes below are for...students and professors.

1. Unlimited iMetrix Pro seats

$\$ 30,000$ annually

Quarterly payment option at no incremental cost

2. 30 iMetrix Pro seats

$\$ 20,000$ annually

Quarterly payment option at no incremental cost

Source: E-mail from representative

\section{CONCLUSION}

To varying degrees, our results suggest that non-trivial differences exist between Compustat and EDGAR Online in terms of data presentation, database development capabilities as well as product pricing. Generally speaking, we believe that EDGAR Online represents a significant competitor to Compustat (although this notion may not be widely held currently). Admittedly, many practitioners as well as researchers may not need financial statement database capabilities. In such cases, the XBRL accounting data provided on the SEC website may suffice.

\section{AUTHOR INFORMATION}

Pavani Tallapally is an associate professor at the Slippery Rock University. Her current research interests include data intermediaries, XBRL and accounting databases. She has presented papers in these areas at numerous academic conferences. E-mail: ptallapally@gmail.com

Michael S. Luehlfing is an associate professor at Louisiana Tech University. His current research interests include various financial reporting and auditing issues as well as various managerial and systems issues. He has published in numerous journals. E-mail: luehlfing@gmail.com

Madhu Motha is an assistant professor at Butler County Community College. His current research interests include bond rating models and XBRL. He has attended numerous academic conferences and presented papers at various conferences. E-mail: madhu.motha@gmail.com 


\section{REFERENCES}

1. Anonymous. (2008). The SEC's IDEA: Replace EDGAR. Information Management Journal 42(6), 13.

2. Kinney, M. R. and Swanson, E.P. (1993). The Accuracy and Adequacy of Tax Data in COMPUSTAT. Journal of the American Taxation Association. 31(3), 309-335.

3. Miguel, J.G. (1977). The Reliability of R\&D Data in Compustat and 10-K Reports. The Accounting Review. (July), 638-641.

4. WebCPAStaff (2009.) SEC Begins XBRL Mandate for First 500 Companies. (February 11, 2009). Available at http://www.accountingtoday.com/news/30734-1.html

5. Yang, D. C., Vasarhelyi, M. A, \& Liu, C. (2003). A Note on the Using of Accounting Databases. Industrial Management \& Data Systems. 103 (3/4), 140-145. 